\title{
Social Computing: The Impact on Cultural Behavior
}

\author{
Naif Ali Almudawi \\ Department of Computer Science and Information System \\ Najran University \\ Najran, Saudi Arabia
}

\begin{abstract}
Social computing continues to become more and more popular and has impacted cultural behavior. While cultural behavior affects the way an individual do social computing, Hofstede's theory is still prevalent. The results of this literature review suggest that, at least for several cultural dimensions, some adjustments may be required to reflect current time and the recognition of the role of technology nowadays. Thus, today, social computing has evolved into continuous communication and interaction of many culturally diverse users.
\end{abstract}

Keywords-social computing; Web 2.0; cultural behavior; culture; Power distance; Individualism vs. collectivism; masculinity vs. femininity; uncertainty; avoidance and time horizon

\section{INTRODUCTION}

\section{A. Social computing}

Social computing has been defined a number of ways by many different people, both scholars and practitioners. According to [9] social computing can also be defined as a communication that is computer-mediated and facilitates the interaction between how humans coordinate, collaborate and distribute news. Another more recent definition of social computing is that social computing is considered an area in the field of computer science that displays the connection of social behavior and computational systems [2]. Definition of social media, or Web 2.0 technologies, is Information and Communications Technology (ICT) that helps to advance both knowledge sharing and learning [18]. Social computing has the ability to promote a transition from a broadcast model of communication to a many-to-many model that allows individuals to converse and receive wisdom from others [20]. Social computing is interactive and collaborative behavior between technology and people. Personal computing is an individual user activity in that one user generally, commands computing. In social computing, the Internet allows users to interact through many mediums, including: Social media sites, Blogs and Wikis [69].

Organizations can use applications such as RSS feeds, podcasts, and blogging to rapidly push content to subscribers all over the world [3],[4],[17],[21]. Web 2.0, or social computing, could also be defined as a conceptual framework where a group of web-based tools could help users collaborate on tasks, interact in social networks, work and rework existing content, as well as share a host of information [6],[12]. All of these help in understanding what is meant by social computing; however, there are many types of social computing tools that are discussed in the literature review proper section.

Thus, social computing, often referred to as Web 2.0 or social media, is continuing to emerge as a new field of computing systems used for modeling social behavior through the use of software and technology. There are many different types of social computing technologies to include blogs, email, wikis, social networking, instant messaging, social bookmarking, and various others. Defined social computing as an enabler for people all around the world to communicate and share information instantly with a common interest or goal and with minimal costs [2],[3]. Some of the most important characteristics of social computing can be summarized as user-created content where users can control the data, unique sharing of content or media, the ability to tap into the intelligent minds of other users collectively, unique communication and collaborative environment, major emphasis on social networks, and an interactive, user-friendly interface [14].

\section{B. Culture}

Culture has been defined in a different way, which refers to the cumulative deposit of knowledge, understanding, principles, values, attitudes, religion, roles, concepts of the life, and possessions acquired by a group of people in the course of generations through group striving and individual [68].

Current research in Computer Information Systems (CIS) has examined the effect of culture in the adoption and use of different social computing technologies. However, research examining the impact of social computing on culture is more limited, albeit increasingly common in recent years. Search engine portals and e-commerce sites are universal internet destinations. Search engines assist in retrieving on-line information, regardless of the location or cultural background of the users. Most search engine technologies were originally developed in the United States, and therefore, intentionally or not, there are designs features embedded in these systems that reflect values that are characteristic of American culture.

Consequently, the cultural background of an individual affects on-line behavior. Nationality, a proxy for culture, has been reported to affect on-line behavior [16]. While the technology is identical everywhere, the way users perceive and use a particular technology varies. Some search engine users may select and emphasize using particular features of the search engine, while others may choose other features. For example, it has been observed that queries placed by users in the United States are likely to contain more operators (include, exclude, wildcard, etc.) than queries placed by users in Europe [53]. Furthermore, culture influences the perception that users develop about systems. Such is the case with: 
- Social computing user perception of the effort required to use the search engine;

- Performance gain obtained when using a search engine; Other's perception of how the system should be utilized and;

- Perception of the individual about the support provided by the surrounding organization infrastructure to use the search engine.

These are all examples of variables that are influenced by a user's culture. System usage is also influenced by variables which include age, gender, and Oexperience [19]. Cultural background also influences the use of a system, as evidenced by the literature that examines system use and culture. According to [11] cultural background is composed of different dimensions, including individualism/collectivism, time orientation, power distance, masculinity/femininity, and uncertainty avoidance. These dimensions are described below in this literature review. This research seeks to understand how social computing impacts the variables identified by Hofstede.

The primary objective of this literature review is to investigate the impact of social computing on cultural behavior. In this review I highlight the prevalent position that social computing plays an impact on the cultural behavior of all human endeavors. Following this, I provide a brief definition of social computing and cultural behavior to justify the important effect that it has in all human endeavors.

\section{LITERATURE REVIEW}

Two areas of investigation make up the focus of this research: social computing and cultural behavior. Thus, the goal of this paper is to provide a review of previous work on both of these domains. We also look at the field of information retrieval, which precedes search engine research. The most significant frameworks proposed to explain cultural behaviors are reviewed, along with the seminal research that grounds this field. Computer information systems research using these well-accepted frameworks is also reviewed.

\section{A. Overview of Social Computing Tools}

Social computing, often referred to as social media or Web 2.0, has evolved greatly since 1966 with the ability to transfer Email messages between users on different computers [9]. Nowadays, there are various types of social computing tools that are used every day by organizations and individuals to include social networks, blogs or weblogs, wikis, instant messaging, and similar tools [7].

According to [1] a vast majority of these technologies are used to improve collaboration and communication efforts within most organizations. The transformation of the Internet with the introduction of social computing has been able to allow passive citizens because active content creators while also providing a greater sense of interactivity [10].

1) Social networks

Social networks are used all over the world to help people connect, meet, and share amongst each other. [8] Described social networking as the way people connect with one another through friendships, common interests, or ideas. Social networking applications can provide a collaborative work environment where individuals can share knowledge and ideas quickly and conveniently [13]. In addition, these can also allow one to quickly gather information about who they know and what they know in organizations [5]. These types of networks are said to exist because humans require social relationships with other humans for survivability.

Social networking sites are basically web-based services that allow individuals to do three things: (a) develop a public or semi-public profile within a system, (b) specify a list of other uses with whom they share a common connection, and (c) view and navigate through their list of connections and those made by others within a particular system [26] There are many applications social networks could be used for, such as a collaboration tool for education and as well as fighting crimes (World Future Society, 2010). Individuals typically create accounts on social networking sites to set up their personal profile. This profile showcases their profile to their online network of 'friends' or peers, many of whom they have preexisting off-line relationships with. Through this initial network, individuals can then gain access to their friends' networks of friends, colleagues, and/or peers so that individuals are open to an array of diverse content through the weaker relationship ties [22]. Although these connections may vary from site to site, these social networking sites mainly help establish or maintain a means of communication through many networks.

Social networking sites are often used to catch up on personal information and current activities of those who have social ties. According to [23] users of social networking sites are usually readily disclose of private information for enjoyment and also for the convenience of establishing and maintaining friendships. They are not only used for social and playful uses, but also used as sources of information and productivity for those business-oriented social networking sites such as LinkedIn and Beehive [24].

Many users of social networking sites use these sites to connect with friends and colleagues they may have previously known [22]. 'Face to face' communication happens less often because of life's circumstances and the limited amount of free time available. Virtual communication is becoming increasingly popular because people spend a lot more time on the Internet with most of that time being spent on social networking sites. According to [25] a study conducted by blog.compete.com in 2011 revealed $75 \%$ of the time users spend on the Internet is being used for social networking. This shows just how much social networking has become a part of everyday life for many people.

There are multiple social networking tools that can be found on the Internet to include Facebook, Twitter, LinkedIn, Myspace, and much more. Although Twitter is a popular social networking tool used by many, Facebook stands out among the rest with over 1 billion users worldwide (Facebook, 2013). Those individuals that frequent Facebook tend to have a high level of trust in the site [27]. Many of these social networking sites are mostly centered around users so that the connections of the users could potentially reach larger 
audiences with low costs.

\section{2) Blogs and weblogs}

Some of the most visible social computing applications are blogs. Blogs, which began in the late ' 90 s, may be thought of as online journals in which individuals or small groups can publish. They are used to express opinions and share knowledge on any topic in a sequential format that is very similar to a personal diary. The archival, search, and categorization features in blogs help organize the content and retrieve specific information [30]. Those blogs that are popular attract many users that will engage in discussions thereby creating networks of blogs and online communities. Although some blogs are confined to personal expressions of a single person, others tend to stimulate reactions and comments from the readers. Because blogs can be used to convey different types of information, such as personal, public, commercial, and political, it has become a very effective communication tool that is constantly used over the Internet.

Blogs are fundamentally different from how they use to be, and many industries see them much differently from other industries. Research has shown that employees think that blogs are more effective than the traditional forms of communications such as emails or newsletters because they have the opportunity to comment, formulate ideas, and facilitate discussions publicly within an organization [34].

Some may see blogs as a good place to share knowledge, while others user blogs to be able to express themselves and feel a sense of empowerment. Blogging seems to make people more thoughtful and articulate observers of what's going on around them. Users can typically use a web browser to create conversations and reflections with respondents [47]. Blogs also offer the ability to do RSS feeds, which push new postings and reader comments to users automatically through syndicating and aggregating information [28]. According to [29] bloggers typically are motivated to publish information for various reasons to include self-presentation, relationship management, keeping up with trends, sharing information, storing information on the internet, entertainment, and for showing off. Many are able to take part in blogging because the software used to blog has become more technically advanced to allow web pages to be updated rapidly and easily.

\section{3) Wikis}

Wikis are another social computing approach used by many to manage web-based content or for collaborating with others. A wiki is a set of linked Web pages that are created incrementally by a group of collaborating users [30]. Wikis are similar to discussion forums and blogs in some ways because the most recent version reflects the cumulative contributions of all authors [32]. Wikis also allows users to see a history of changes, and if needed, it has the ability to revert pages to previous versions. A simplistic way of describing a wiki is that it is a "web based program that allows viewers of a page to change the content by editing the page online in a browser" [33].

Wiki, derived from the Hawaiian term Wikiwiki meaning "fast", was first developed in 1995 by Ward Cunningham to communicate specifications for software design [30]. Since it was developed, it has become an increasingly popular tool used by many for knowledge sharing and collaboration. One of the most visible instances of the wiki concept is Wikipedia, which provides primers on a wide variety of terms and names. Some key issues surrounding Wikipedia is the quality and credibility of the information being posted [36].

According to [67] warned that wiki users using the created web pages as a sole source of data could potentially diminish cognitive and affective learning outcomes that are assigned as a characteristic of wiki. A wiki can also be used as a collaboration tool. Many researchers have noticed the benefit of using wikis for student-to-student collaboration from elementary to graduate schools [64], [65].

The term "wiki", according to [37] generates roughly 436 million items on the Google search engine. More than 2.8 million English-language articles are in Wikipedia with more than 250 languages represented. The authors also determined that there were just below 13 million users of Wikipedia's English-language, which demonstrates just how important wikis are to users around the world. One of the main uses of a wiki, according to [39] is a content repository where wiki users can contribute their experiences and other content. They can also be used for organizational portals, for managing projects, and for creating a knowledge-base. Because of wikis are Internet-based, much of the content can either be extended within an organizational context or externally for customers and business partners.

Wikis can allow students the ability to share information interactively while fostering the vision of negotiated meaning, knowledge construction, and learner-to learner interaction [49]. Also reported how wikis and other social computing technologies could improve team collaboration, thereby enhancing learning among students. Explored the effect of using wikis on collaborate writing by using two writing tools (a wiki web site and MS Word) and three user modes (face-toface, synchronous distribution, and asynchronous distribution). When comparing MS Word to the wiki web site, the authors found that the face-to-face collaborative writing sessions with wikis led to greater levels of participation. Wikis also produced documents with higher quality and provided greater satisfaction for the contributors. [37].

The private sector is increasingly engaging in the use of wikis to help influence business through innovative ideas and knowledge sharing [63]. According to [62] surveyed 168 corporate wiki users to determine how many are using wikis in a corporate setting. These experienced wiki users spent an average of 15 month contributing to company wikis and about 26 months contributing to wikis in general on average. The authors found that some of the most common activities wikis were used for included software development, e-learning, project management, posting of general information and knowledge management, communities of practice and user groups, ad-hoc collaboration, tech support, marketing and customer relationship management, resource management, and $R \& D$ [62]. The users indicated they benefited from corporate wikis because they enhanced reputation, made work easier, and helped the improvement of organizational processes. These benefits were more likely when wikis were used for those tasks requiring innovative solutions and when 
the posted information was from credible sources.

\section{4) Instant messaging}

One of the most popular forms of social computing is instant messaging (IM). IM is a computer-based communication with fast transmission times that allows users to type messages to other users in a near-synchronous fashion [40] IM is a unique form of social computing because it allows immediate communication; however, it doesn't provide a lot of information about the user such as the profile pages that are involved with the social networking tool, Facebook. In addition to the immediate communication, many IM systems allow others to know users are currently logged in, how long they have been logged in, and if they are active or inactive. Some systems give users the ability to control who can see them online and also block those one may not want to communicate with. This type of social computing, could also be beneficial for those people that are geographically distant and prefer not to incur the financial expenses of face-to-face meetings.

Previous research indicated instant messaging is used in about $85 \%$ of enterprises in North America [50]. IM can function as a task-oriented, communication tool for users in the workplace, while also serving as an informal collaboration tool. Although there are still some organizations that have yet to find the benefit in using IM, there are many who have seen the value and are encouraging employees to use as a means for immediate communication in the enterprise. According to [38] investigated instant messaging to understand the determinants of collective intention, known as we-intention, which represents how someone may perceive a group of people that act as a unit. Based on the critical mass theory and social influence processes, the study's findings illustrated that critical mass influenced we-intention to use instant messaging indirectly and directly through two other factors known as group norm and social identity. The authors noted that understanding and recognizing the importance of collection intention can help managers advance their knowledge beyond that of the individual-based models that are greatly adopted in information systems research.

With the many types of social computing tools available, individuals can effectively collaborate and may change cultural behavior by simply being more innovative and creating an atmosphere that works for one's needs. As technology continues to change, more cultures are starting to embrace the whole idea of social computing and are working to make that a part of everyday life.

\section{B. Benefits and Challenges of Social Computing}

Social computing could be both enriching and challenging for those who utilize these technologies. According to [35] students who have experience using social computing in the classroom typically accept the technology along with its emerging concepts, tactics, and course content available. The authors also explained how social computing could support peer learning. Students had no problems sharing what they learned and provided answers to questions that lessened the strain onfaculty resources. In addition students were also more comfortable asking their peers questions. Blackboard also has a messaging capability that allows students to submit assignments securely and provide a way for faculty to provide feedback in a timely fashion. A ccording to [66] developed a theory that looked at the relationship between emotional capital and internal social media use. Emotional capital was defined in this study as "the aggregate feelings of goodwill toward a company and the way it operates". The authors used comparative case studies and tested this theory using a survey. The findings indicated that executives who utilized social media to build emotional capital within employees were able to benefit in terms of an improvement in information flows, collaboration, lower turnover, and higher employee motivation.

Another potential benefit of social computing in the classroom is the ability of the faculty to manage the students. Recent research has proven how social computing technologies can benefit teaching and learning. Social computing can allow the tracking of student interactions through Blackboard, whichprovides a means for identifying those students who may be failing and to evaluate how the students are. [6]

Some other potential benefits of social computing include having a more flexible organization where employees or students could participate through contributing and providing feedback. Social computing could provide new styles of management where organizations allow the use of social computing for both work and personal use as it was often forbidden in the past. Also social computing could provide new ways to manage digital content by offering new ways of searching, managing, and effectively utilizing the information that is provided. Those organizations that are interested in maximizing the benefits of social computing should seek to integrate these systems with other systems that have similar purposes [44].

\section{Use of culture behavior in Information systems Studies}

An awareness of social computing and its impact on culture behavior is valuable to the understanding of how social computing technologies are used at the national, organizational, and group level and can have an effect in the implementation and use of social computing technologies [16]. First, finding an objective definition of culture has been an elusive task. In their ample review of culture, Note that there exist countless definitions, which relate to ideologies, beliefs, assumptions, shared values, collective will, norms, practices, symbols, language, rituals, myths, and other elements. Definitions come from multiple disciplines including psychology, sociology, anthropology, communication, linguistics, business, and others [16].

While these myriad of definitions exist, several authors agree that culture manifests itself at different levels. These authors agree that these values and assumptions form over time and are deeply embedded in individuals. In fact, these sets of values are acquired early on in life and generally transmitted by those surrounding an individual since infancy. Furthermore, these values and assumptions form a belief system that defines how individuals perceive and relate to each other and to the physical world, and how schemes and strategies are realized. While external circumstances may change during the life of an individual, this belief systems is 
deeply rooted and likely to remain unchanged. In fact, this system is highly internalized by individuals, and it unconsciously influences all activities.

Note that social computing technology is not culturally neutral and "may come to symbolize a host of different values driven by underlying assumptions and their meaning, use, and consequences" [16]. Several definitions of culture have been used in cross-cultural studies in the computer information system literature. Three influential frameworks, those of [11], [51], [52] are cited repeatedly in social computing systems studies dealing with culture. Based on the strong empirical evidence provided, Hofstede's work went on to become ubiquitous within the social computing discipline. According to [51] proposed seven dimensions of culture; some of which overlap with those proposed by Hofstede. The other dimensions proposed dealt with variables not considered in [45] research, such as how individuals from different cultures perceive the world and their surroundings, how individuals from different cultures employ different strategies when thinking and deciding, and how rules and status impact relationships. Table 1 provides a short summary of conceptualization of culture.

\section{TABLE I. TROMPENAARS DIMENSIONS OF CULTURE (ADAPTED)}

\begin{tabular}{|l|l|}
\hline Dimension & Definition \\
\hline $\begin{array}{l}\text { Universalism vs. } \\
\text { Particularism }\end{array}$ & $\begin{array}{l}\text { The extent to which rules and norms apply to } \\
\text { everyone equally and the ability to make } \\
\text { exceptions for some. Individuals in a society may } \\
\text { apply rules and norms equally among all } \\
\text { members, regardless of their position, status, or } \\
\text { relationship, or may make special exclusions and } \\
\text { adjustments for specific cases. }\end{array}$ \\
\hline $\begin{array}{l}\text { Analyzing vs. } \\
\text { Integrating }\end{array}$ & $\begin{array}{l}\text { Starting with the whole and decomposing into } \\
\text { parts, or integrating the parts into the whole. } \\
\text { Societies may tackle problems by taking a top } \\
\text { down, or bottom up approach. }\end{array}$ \\
\hline $\begin{array}{l}\text { Individualism vs. } \\
\text { Communitarianism }\end{array}$ & $\begin{array}{l}\text { The rights and desires of the individual versus the } \\
\text { rights and desires of the group. Individuals in a } \\
\text { society may be willing (or not) to sacrifice } \\
\text { personal goals for the goals of the group. }\end{array}$ \\
\hline $\begin{array}{l}\text { Inner-directed vs. } \\
\text { outer-directed }\end{array}$ & $\begin{array}{l}\text { The search for answers using thinking, intuition, } \\
\text { and personal judgment, or to seek data in the } \\
\text { outside world. In solving problems, a group may } \\
\text { resort to their own insights, or to the physical } \\
\text { world and empirical data. }\end{array}$ \\
\hline $\begin{array}{l}\text { Time as sequence vs. } \\
\text { time as } \\
\text { synchronization }\end{array}$ & $\begin{array}{l}\text { Events happen in different time periods in a } \\
\text { sequential fashion, or events may overlap and } \\
\text { occur in parallel. In a society, every event and } \\
\text { action is an individual unit that requires exclusive } \\
\text { attention, or a individual or group could focus on } \\
\text { many events and actions }\end{array}$ \\
\hline $\begin{array}{l}\text { Achieved status vs. } \\
\text { ascribed status }\end{array}$ & $\begin{array}{l}\text { Gaining status and recognition based on effort } \\
\text { and performance, or by right Rank and standing } \\
\text { is the result of either effort or performance, or it } \\
\text { is inherited. }\end{array}$ \\
hierarchy & $\begin{array}{l}\text { Equality among all members of the group, or } \\
\text { ranks that distribute power. The distribution of } \\
\text { power is a society may vary by concentrating } \\
\text { authority on certain groups or distributing it } \\
\text { among members. }\end{array}$ \\
\hline
\end{tabular}

Most computer information systems research dealing with cultural behavior will employ one of these frameworks, with
Hofstede's dimensions of culture being the most prevalent [16]. Hofstede's dimensions of culture, as the most dominant framework, will be reviewed in the next section.

\section{Hofstede's Culture Dimensions}

There are multiple conceptualizations of culture. In this review we have presented those that are not only relevant, but have been widely used in computer information systems research. General agreement exists that the most commonly used definition of culture states that culture is "the collective programming of the mind, which distinguishes the members of one category of people from another" [11]. This programming extends from language and symbols to patterns and interactions. Hofstede's conceptualization of culture has been used extensively inside and outside of the field of computer information systems [16].

Hofstede's research involved more than 100,000 respondents from over 70 nationalities and more than 20 languages. The data collected resulted in the development of a model which includes five dimensions which can be used to measure national culture. Hofstede describes these dimensions as Power Distance (PD), Individualism versus Collectivism (IC), Masculinity versus Femininity (MC), Uncertainty Avoidance (UA), and Time Horizon (TH). These dimensions are summarized in Table 2.

TABLE II. HofSTEDE’S (1980) CULTURAL DiMENSIONS (ADAPTED)

\begin{tabular}{|l|l|}
\hline \multicolumn{1}{|c|}{ Dimension } & \multicolumn{1}{c|}{ Definition } \\
\hline $\begin{array}{l}\text { Power } \\
\text { distance }\end{array}$ & $\begin{array}{l}\text { The degree to which the less powerful members of a } \\
\text { society expect differences in the levels of power } \\
\text { [hierarchical (authoritarian) or equalitarian (follower)]. } \\
\text { The likelihood that an individual with less power (at a } \\
\text { lower point in the hierarchy) can influence decisions } \\
\text { made by those with more power (at a higher point in the } \\
\text { hierarchy) }\end{array}$ \\
\hline $\begin{array}{l}\text { Individualism } \\
\text { vs. } \\
\text { collectivism }\end{array}$ & $\begin{array}{l}\text { The extent to which people are expected to stand up for } \\
\text { themselves, or act predominantly as a member of the } \\
\text { group or organization. The willingness of an individual } \\
\text { to sacrifice their own personal interests for the interests } \\
\text { of the group and vice versa. }\end{array}$ \\
\hline $\begin{array}{l}\text { Masculinity } \\
\text { vs. Femininity }\end{array}$ & $\begin{array}{l}\text { The role overlaps that may exist among male and } \\
\text { female members of a society.Masculine cultures value } \\
\text { competitiveness, ambition, } \\
\text { accumulation of wealthess, and material } \\
\text { possessions.Feminine cultures value relationships, } \\
\text { quality of life, commitment, charity, compromise, and } \\
\text { relationship building. }\end{array}$ \\
\hline $\begin{array}{l}\text { Uncertainty } \\
\text { avoidance }\end{array}$ & $\begin{array}{l}\text { How societies attempt to cope with anxiety by } \\
\text { minimizing uncertainty.The level of risk taking and risk } \\
\text { tolerance of a society. The strategies to minimize } \\
\text { uncertainty include laws, rules and structures that limit } \\
\text { outcomes }\end{array}$ \\
\hline Time Horizon & $\begin{array}{l}\text { Describes a society's time horizon and the willingness of } \\
\text { individuals to sacrifice long-term goals for short-term } \\
\text { goals and vice versa. }\end{array}$ \\
\hline
\end{tabular}

The national cultural dimensions presented by Hofstede have been used repeatedly in cross-cultural studies in many disciplines, including Computer Information System research 
[16]. It is possibly the most cited and used work in the field of cross-cultural research [11]. These variables and dimensions, which distinguish cultures, are described below.

\section{1) Power Distance}

Cultural behavior affects the way decisions are made. While the studies reviewed did not examine the impact of power distance on search engine technology, several studies in information systems have linked power distance and participation in Group Decision Support Systems (GDSS). For example, explored whether the use of a GDSS would attenuate power distance. When using a GDSS, all users are presented at the same hierarchical level (organization-wise). If so, users may feel more comfortable expressing opinions. The effect of a GDSS would therefore be more pronounced in cultures with high power distance [56].

Power distances may also influence the process for selecting strategies to deal with complex problems and situations. In low power distance environments, assertive and control-oriented strategies take place more frequently [54]. In high power distance environments, assertive and control those who have a higher hierarchical status only take oriented strategies. In low power distance environments, any individual can propose strategies and take leadership, since decision making power is equal among members of a group.

\section{2) Individualism versus Collectivism}

Collectivist cultures tend to approach tasks, problems, and solutions as a group, sharing information in order to make decisions. Individuals from individualistic cultures prefer to undertake problems by themselves. Consequently, there is more shared meaning and common knowledge in an organization composed of collectivist members than in an organization composed of individualistic members. Based on this, we expect members of an individualistic culture to rely more on information systems to obtain information to make decisions than those of collectivist cultures, who gather/share information from/with each other [15].

In collectivist cultures, the amount of shared context or knowledge between participants in a dialogue is significantly higher than in individualistic cultures. In high context cultures, meaning is derived from the context of a communication exchange [42]. For collectivist cultures, where context is high, individuals share a vast array of information, which creates, shared knowledge while in low context communication is predominant in individualistic societies. High-context communication is prevalent in collectivistic cultures [42].

In high context cultures, implicit information is shared and the communication process relies on understanding the meaning of the verbal messages as well as interpreting cues such as tone of voice, body language, facial expressions, voice patterns, the use of silence, and past interactions. These cues, when understood, transmit information that would otherwise need to be encoded verbally. Participants of a conversation capture information from reading these cues from each other, which would be unnoticeable to those who do not share the same context.

While collectivist cultures are generally regarded as high context cultures, individualistic cultures can generally be classified as low context cultures. In these, individuals have limited shared knowledge, or assume a limited shared knowledge. Verbal messages are the primary communication medium. Other cues are not as important, and are sometimes blocked. Individuals in low context cultures generally opt for a reduced number of non-verbal cues since non-verbal cues could transmit equivocal messages due to the lack of common context. For these cultures all information needs to be communicated explicitly since there are few shared codes and symbols. When communicating, there is only one literal meaning to a message, and the meaning is not affected by occasional non-verbal cues that may be transmitted simultaneously [55].

The impact of technology adoption is moderated by culture, and individualism and collectivism have an impact. Individuals who come from collectivist cultures will provide information and seek approval from the members within their social boundaries, the "in-group", and will discard those who are outside of the social boundaries, the "out-group". Those who come from cultures characterized as individualist will give equal value to those in the in-group as to those in the outgroup. The previously mentioned behavior has been reported in collaborative search environments, where those who were characterized as collectivist exchanged more information with their in-group. On the other side, those characterized as individualist did not give preference to any group. For collectivist cultures technology usage is perceived as a means to achieve organization among the group, with emphasis on the group. Individualistic cultures see technology as a means to achieve individual efficiency and decision making [61]. More specifically to on-line search behavior, members of collectivist cultures would find relevance ratings constructed from other users' opinions more trustworthy than relevance ratings constructed with measures such as number of hits. Therefore, collectivist cultures are likely to value a search engine that presents relevance rating based on other's opinions, and vice versa.

\section{3) Masculinity versus Femininity}

The level of masculinity or femininity of a culture has been linked to behavior in GDSS. Members of masculine cultures value recognition [48]. A GDSS meeting in which the anonymity feature is enabled will result in reduced participation from participant who reflects values associated with masculinity cultures [48] Furthermore, such an anonymous GDSS meeting will encourage masculine members to "free-ride", while member who reflect values associated with low masculinity cultures will contribute to ensure the "well-being" of the group. Individuals from feminine cultures will also appreciate anonymity because they fell that this setting creates less conflict. In a different setting, individuals from masculine cultures tended to generate more conflict than individuals from cultures that are classified as low in masculinity. In addition, individuals from masculine cultures propose fewer conflict resolution strategies than other participants [60].

Furthermore, it has been reported that in some groups, time dominance, which is the time allocation obtained by contentious techniques such as raising the voice, is decreased since a GDSS system may be unable to transmit these cues 
[58]. In such environments members of masculine cultures tended to participate less than members of feminine cultures. Based on the research described above, assertiveness and aggressiveness, which are values associated with masculine cultures, are difficult to convey in these media.

Another study analyzed web sites and their manifestation of masculine and feminine values [31] In this research, several websites were analyzed and masculine and feminine "signifiers" were found. Several masculine cultural values were identified such as strength, challenge performance, dominance, success, and leadership. The feminine values identified were sympathy for the weak, charity, relationship, commitment, sharing, and concern for life. The study found that those websites that were categorized as masculine generally contained numerical and statistical information and tables to describe events and facts. Masculine cultures tend to rely on factual information. The websites that were categorized as feminine generally resorted to intuition and feelings when describing events and facts [31]. Sites classified as masculine and feminine also used different tones to communicate, where words may be emphasized by using bold typefaces, and exclamation marks. This is in addition to the use of an assertive tone and challenging, sarcastic, and ironic comments to justify claims. Feminine websites were found to resort to explanation to justify a claim, and deferring explanation to experts, if necessary.

Feminine cultures value relationships. In those websites that were categorized as feminine, the language intended to build a relationship with the reader. Articles such as "you" were used often, as opposed to "one"

which was more common in websites that were categorized as masculine. In addition, imperatives, which show power and assertiveness, were more frequent in masculine rated web sites. The amount of dependence and fixation on technology by a culture is also a result of the level of masculinity/femininity. Masculine cultures tend to be more technology focused [46] Feminine cultures also value technology, but emphasis is placed on users and relationships. Masculine cultures may evaluate a technology by examining quantitative performance; while feminine cultures evaluate a technology by looking at the impact it has on its users and the workplace.

\section{4) Uncertainty Avoidance}

Uncertainty avoidance has been examined by Information System research. Technology adoption and diffusion has been linked to the uncertainty avoidance level of the culture. The adoption of certain technologies may take longer in some cultures, where users need to have certain assurances about a technology before the technology is widely adopted and standardized.

Hofstede determined that a culture with a high level of uncertainty avoidance generally prefer rules and structure, and enjoy having a higher degree of control. Individuals that are characterized as high in uncertaintyavoidance will require a larger number of searches to come to a conclusion (Wilson). Individuals that rate low on the uncertainty avoidance dimension will come to a conclusion with a lower number of search iterations. In addition, the risk profile of an individual can be weighed against the potential social impact of a decision.Individualistic cultures value risk taking and confrontation which may result in increasing personal benefits while harming the status of other [43].

\section{5) Time Horizon}

Culture influences an individual's acceptance of different time horizons or outcome expectations. An individual who comes from a short term oriented culture places more value on immediate results which are tangible. A higher value is given to any method or strategy that will provide immediate results. Efficiency is a key aspect of a process, and it is as important as the final result (Hofstede). Cultures that exhibit values of long term orientation uphold that perseverance, persistence, and thrif are necessary to achieve goals. Immediate satisfaction is not seen positively, since all future rewards should be the result of present effort. In contrast with short term oriented cultures, shortcuts are not acceptable, and may be considered dishonest.

In short term oriented cultures, the criteria used by an individual to evaluate the quality of a method, process, or service received will place more weight on delivery time. On the other hand, an individual who belongs to a long term oriented culture will not be concern with the time period required to complete a process or service, as long as the end result is what is desired.

An individual's time horizon has been evaluated in the context of on-line shopping, within the context of TAM, where a user's degree of time orientation moderated the relationship between trust and intention to use [59]. These results are significant because they suggest that in cultures that are long term oriented, trust is more important than perceived ease of use and perceived usefulness, within the TAM framework.

Time orientation has also been researched in the context of computer security. Long term horizon societies tend to have a different disposition and awareness in regards to potential threats to computer systems. Research has shown that in Asian cultures, which rate as long term oriented cultures, it would be more effective to describe long term benefits of an adequate computer security policy, than the immediate benefits [41].

\section{SUMMARY}

This paper provided a discussion of social computing and how it has been defined over the years. It also emphasized that described some of the social computing tools that are available and their potential uses. Additionally, This paper described a culture and cultural behavior with Hofstede's culture dimensions as conceptualizations of culture. In this paper concluded by presented those cultural dimensions that are not only relevant, but have been widely used in computer information systems research.

Social computing is an active area of research. In light of ongoing developments in on-line technology and new applications, many users switch from searching as application (e.g. Google) to searching as a function of an advanced, more complex system (e.g. Facebook's search function). This paradigm switch may require review of survey instrument in 
future research. This literature review is based on Hofstede's model developed more than three decades ago. While the model has been repeatedly updated, changes may not have taken into consideration all newly developed technologies. In particular social computing technologies such as social networking applications, which re-defined the concept of personal computing and empower members of cultures that reflect collectivist values. Also, acceptance and use of new technologies will affect user behavior and consequently new or modified hypotheses will need to be developed. A potential area or future review may concentrate on a particular application of social coimuting such as search engines or social networking, and nclude a modified Hofstede's instrument to specifically address the advances of computation technology.

\section{REFERENCES}

[1] S. Andriole, "Business impact of Web 2.0 technologies." Communications of the Association for Computing Machinery, vol. 53, pp.67-79., 2010.

[2] M. Banan and A. Banan, "What about correlation between metrics and social computing?ComputerScience \& Telecommunications. [On-line]. 6, pp. 47-55., 2009.

[3] N. Barnes and E. Matson, "Social media in the 2009 Inc. 500: New tools and new trends. University of MA Dartmouth, Center for Marketing Research.

[4] N. G. Barnes \& E. Matson,"The Fortune 500 and social media: A longitudinal study of blogging and Twitter usage by America's largest companies. Unpublished research report.

[5] M. Brandel. Social networking goes corporate. ComputerWorld, 42(32), 24-27., 2008.

[6] L.Buffington, Creating and consuming Web 2.0 in art education. Computers in the Schools, 25(3), 303-313., 2008.

[7] J. Bughin, J.Manyika, and A. Miller. (2008). Building the Web2.0 enterprise.

[8] Coyle, and H. Vaughn, "Social networking: Communication revolution or evolution? " Bell Labs Technical Journal, 13(2), 13-17., 2008.

[9] Culley, (2006). Social computing. Retrieved from http://www.instructionaldesign.com.au/Academic/SocialC omputing.htm

[10] M. Dadashzadeh, Social media in government: From eGovernment to eGovernance. Journal of Business \& Economic Research, 8(11), 81-86., 2010.

[11] G. Hofstede, Culture Consequences Sage, Beverly Hills, CA., 1980.

[12] Jonassen, Howland, J., Marra, and D. Crismond, Meaningful learning with technology. Upper Saddle River, NJ: Pearson, Prentice Hall.2008.

[13] J. Kratzer, R. Leenders, nad j Van Engelen, The social network among engineering design teams and their creativity: A case study among teams in two product development programs. International Journal of Project Management, 28(5), 428-436. 2010.

[14] L. Lai, nad E. Turban, Groups formation and operations in the web 2.0 environment and social networks. Group Decision and Negotiation, 17(5), 387- 402., 2008.

[15] Leidner, H. Koch, and E Gonzalez, Assimilating Generation Y IT new hires into USAA's workforce: The role of an Enterprise 2.0 system. MIS Quarterly Executive, 9(4), 229-242.,2010.

[16] D. Leidner, and T. Kayworth, "Review: A Review of Culture in Information Systems Research: Toward a Theory of Information," Management information systems quarterly. (30:2) 2006, pp 357-399.

[17] Ramdani, nad T. RajwaniEnterprise 2.0: the case of British Telecom. Journal of Strategic Management Education, 6(2), 135-148., 2010.

[18] O. Serrat, Social media and the public sector. Washington, DC: Asian Development Bank. 2010.

[19] Venkatesh, J. Thong, and X. Xu, Consumer acceptance and use of information technology: Extending the unified theory of acceptance and use of technology. MIS Quarterly, 36(1), 157-178.,2012.

[20] T. Williams, R. Williams, Adopting social media: Are we leaders, managers, or followers? Communication World, 25(4), 34-37.,2008.

[21] M. Zeisser, Unlocking the elusive potential of social networks. McKinsey Quarterly. 2010.

[22] N. Ellison, C. Steinfield and C. Lampe The benefits of Facebook "friends:" Social capital and college students' use of online social network sites. Journal of Computer- Mediated Communication. Jul1;12(4):1143-68., 2007.

[23] H. Krasnova, S. Spiekermann,K. Koroleva andt Hildebrand, Online social networks: why we disclose. Journal of Information Technology. 2010 Jun 1;25(2):109-25.

[24] J. DiMicco, D. Millen, W. Geyer, C. Dugan, B. Brownholtz, and M.Muller, November. Motivations for social networking at work. InProceedings of the $2008 \mathrm{ACM}$ conference on Computer supported cooperative work (pp. 711-720).

[25] L. Chiş, M. Talpoş, "PROS AND CONS OF CORPORATE SOCIAL NETWORKING." Review of Management \& Economic Engineering10, no. $2,2011$.

[26] N. Ellison, and D. Boyd. ". Sociality through Social Network Sites." 2013.

[27] J. Fogel, and E. Nehmad, CInternet social network communities: Risk taking, trust, and privacy concerns. Computers in human behavior25(1), pp.153-160., 2009.

[28] T. Kidd, and I. Chen, Wired for learning: an educator's guide to web 2.0. IAP; 2009.

[29] Lee, S,Im, C. Taylor. Voluntary self-disclosure of information on the Internet: A multimethod study of the motivations and consequences of disclosing information on blogs. Psychology \& Marketing. 2008 Jul 1;25(7):692-710.

[30] H. Du andC. Wagner, Learning with weblogs: An empirical investigation. InProceedings of the 38th Annual Hawaii International Conference on System Sciences 2005 Jan 3 (pp. 7b-7b). IEEE.

[31] Zahedi, W. Van Pelt, and M. Srite, Web documents' cultural masculinity and femininity. Journal of Management Information Systems, 2006, 23(1), pp.87-128.

[32] O. Arazy, I.Gellatly, S.Jang, and R. Patterson, Wiki deployment in corporate settings. IEEE Technology and Society Magazine, 28(2), pp.57-64.,2009

[33] Ebersbach, M.Glaser,R. Heigl, and A. Warta, Wiki: web collaboration. Springer Science \& Business Media. 2008.

[34] Zhang ,Y. Zhu, and H. Hildebrandt, Enterprise Networking Web Sites and Organizational Communication in Australia. Business Communication Quarterly. 2009;72(1):114-9.

[35] Okoro, A. Hausman, and M. Washington. Social media and networking technologies: An analysis of collaborative work and team communication. Contemporary Issues in Education Research (Online). 2012 Jul 1;5(4):295.

[36] M. Parameswaran and A.Whinston, Research issues in social computing. Journal of the Association for Information Systems, 8(6), p.336., 2007.

[37] S. Chu, Y. Kim, Determinants of consumer engagement in electronic word-of-mouth (eWOM) in social networking sites. International journal of Advertising. 2011 Jan 1;30(1):47-75.

[38] X. Shen, C. Cheung, and M. Lee, Perceived critical mass and collective intention in social media-supported small group communication. International Journal of Information Management. 2013 Oct 31;33(5):707-15.

[39] R. Rubio, S. Martín, and S. Morán, Collaborative web learning tools: Wikis and blogs. Computer Applications in Engineering Education. 2010 Sep 1;18(3):502-11.

[40] B.Nardi, S.Whittaker, and E. Bradner, Interaction and outeraction: instant messaging in action. InProceedings of the $2000 \mathrm{ACM}$ conference on Computer supported cooperative work 2000 Dec 1 (pp. 79-88). ACM.

[41] M. Schmidt, A. Johnston, K. Arnett, J. Chen, and A. Li ,cross-cultural comparison of us and chinese computer security awareness. Journal of 
Global Information Management. 2008 Apr 1;16(2):91.

[42] W. Gudykunst,. and Y. Kim, Communication with Strangers: An Approach to International Communication. 2008.

[43] Adams G, Gercek-Swing B. Avoid or Fight Back? Cultural Differences in Responses to Conflict and the Role of Collectivism, Honor, and Enemy Perception Ceren Günsoy Susan E. Cross Ayse K. Uskul 2.

[44] J. Blackwell, J. Sheridan, K. Instone, D. Schwartz, S. Kogan, Design and adoption of social collaboration software within businesses. InCHI'09 Extended Abstracts on Human Factors in Computing Systems 2009 Apr 4 (pp. 2759-2762). ACM.

[45] G.Hofstede, Culture and organizations. International Studies of Management \& Organization. 1980 Dec 1;10(4):15-41.

[46] Hasan, G.Ditsa, The impact of culture on the adoption of IT: An interpretive study. Journal of Global Information Management (JGIM). 1999 Jan 1;7(1):5-15.

[47] W. Richardson, Blogs, wikis, podcasts, and other powerful web tools for classrooms. Corwin Press, 2010.

[48] R. Robichaux, and N. Keesee, What can social workers do for warriors in transition?. US Army Medical Department Journal. 2008 Jan 1:25-7.

[49] C.Tu, M. Blocher, and G.Roberts, Constructs for Web 2.0 learning environments: A theatrical metaphor. Educational Media International. 2008 Dec 1;45(4):253-69.

[50] P.To, C. Liao, C. Chiang, M. Shih and C. Chang, An empirical investigation of the factors affecting the adoption of Instant Messaging in organizations. Computer Standards \& Interfaces. 2008 Mar 31;30(3):148-56.

[51] P. Smith, S. Dugan, and F. Trompenaars, National culture and the values of organizational employees a dimensional analysis across 43 nations. Journal of cross-cultural psychology. 1996 Mar 1;27(2):231-64.

[52] W. Gudykunst, S.Ting-Toomey, and E.Chua, Culture and interpersonal communication. Sage Publications, Inc; 1988.

[53] S. Koshman, A. Spink, and B. Jansen, Web searching on the Vivisimo search engine. Journal of the American Society for Information Science and Technology. 2006 Dec 1;57(14):1875-87.

[54] S. Singh, Cultural differences in, and influences on, consumers' propensity to adopt innovations. International Marketing Review. 2006 Mar 1;23(2):173-91.

[55] S. Singh, Cultural differences in, and influences on, consumers' propensity to adopt innovations. International Marketing Review. 2006 Mar 1;23(2):173-91.

[56] Smith, and I. Walker I. The Rocky Road from Comparisons to Actions. Improving intergroup relations: Building on the legacy of Thomas F. Pettigrew. 2008 May 30;2:227.

[57] Karahanna, J. Evaristo, and M. Srite, Levels of culture and individual behaviour: An integrative perspective. Advanced Topics in Global Information Management. 2006 Apr 30;5(1):30-50.

[58] Robichaux and R. Cooper, "Gss Participation: A Cultural Examination " Information \& Management (33:6) 2008, pp 287-300.

[59] Yoon. "The Effects of National Culture Values on Consumer Acceptance of ECommerce: Online Shoppers in China," Information \& Management (46:294-301) 2009.

[60] L. Tunga and M. Quaddus, "Cultural Differences Explaining the Differences in Results in Gss: Implications for the Next Decade " Decision Support Systems (33:2) 2005, pp 177-199.

[61] H. Cho, and J. Lee, "Collaborative Information Seeking in Intercultural Computer Mediated Communication Groups: Testing the Influence of Social Context Using Social Network Analysis," Communication Research. (35:4) 2008, pp 548-573.

[62] Majchrzak, C. Wagner, \& D. Yates .Corporate wiki users: results of a survey. Proceedings of the 2006 international symposium on Wikis. Odense, Denmark. Retrieved from ACM Digital Library. 2006.

[63] Kane. A multimethod study of information quality in wiki collaboration. ACM Transactions on Management Information Systems, 2(1). 4.2011.

[64] Collier. Wiki technology in the classroom: Building collaboration skills. Journal of Nursing Education, 49(12), 718-718.

[65] Morgan \& R. Smith,. A wiki for classroom writing. The Reading Teacher, 62(1), 80-82.2008.

[66] Q. Huy and A. Shipilov. The key to social media success within organizations. MIT Sloan Management Review. 2012 Oct 1;54(1):73.

[67] B. Alexander. Social networking in higher education. In R. N. Katz, (Ed.), Thetower and the cloud: Higher education in the age of cloud computing (pp. 197- 201). 2010.

[68] P. McFarlane. "Developing a culturally specific e-learning website." In2006 7th International Conference on Information Technology Based Higher Education and Training, pp. 473-480. IEEE, 2006.

[69] Dix, Human-computer interaction, pp. 1327-1331, Springer US,2009. 